\title{
THE COVID-19 PANDEMIC, PERSONAL PROTECTIVE EQUIPMENT, AND RESPIRATOR: A NARRATIVE REVIEW
}

\author{
Jennifer $\mathrm{Ha}^{1}$ \\ ${ }^{1}$ Affiliation not available
}

April 28, 2020

\begin{abstract}
The coronavirus disease 2019 (COVID-19) pandemic has touched almost every continent. Personal protective equipment $(\mathrm{PPE})$ is the final line of protection of healthcare workers $(\mathrm{HCW})$. There is variation as well as controversy of infection control recommendation with regards to the use of PPE for HCW between institutions. The aim of this narrative review is to of examine and summarise the available evidence to guide recommendation for the safety of HCW. A literature search was conducted on the PubMed, MedLine, and Embase databases with the keywords "personal protective equipment", "COVID 19", "n95", "health care worker", and "mortality". SARS-nCoV-2 is highly contagious. 3.5-20\% of HCW has been reported to be infected. The mortality ranges from $0.53-1.94 \%$. PPE is part of the measure within a package of prevention and control of pandemic, rather than a replacement of. Respirators are more effective than masks in preventing aerosol transmission to HCWs. Extended use may be considered if guidelines are adhered. PAPRs if available should be used in high risk procedures. Transmission of viruses is multimodal, and in the setting of a novel pathogen with high case fatality with no proven effective interventions, PPE that affords the best protection should be available to HCWs.
\end{abstract}

\section{KEYWORDS}

COVID-19, respirator, personal protective equipment, health care worker, N95

\section{INTRODUCTION}

The coronavirus disease 2019 (COVID-19) pandemic has touched almost every continent. The transmission can be reduced through exposure control by means of engineering, administrative, and environmental controls.(1) Personal protective equipment (PPE) is the final line of protection of healthcare workers (HCW) especially in the community transmission phase of the COVID-19 pandemic.

The key to a public health emergency response lies in the abundance of reserves, proper allocation of emergency medical supplies and rapid distribution.(2) Some countries have a national medical stockpile of key reserves of essential medications and equipment like PPE.(2) While this is an indispensable element of public health emergency response, when the system is tested, this has been found to be lacking. This was seen during the H1N1, SARS-CoV-1, and now the SARS-CoV-2 pandemic. There is a global shortage of PPE for HCW, resulting in transmission of the disease, reducing the available frontline HCWs who care for these patients, resulting in the transmission of disease to their families and communities, as well as resulting in $\mathrm{HCW}$ mortality.

While financial considerations, PPE supply, and logistics are important, healthcare systems also have occupational health and safety obligations to their HCWs and reassurance that they are using the highest level of protection and not putting themselves, their families or colleagues at risk.(3)

Currently, there is variation as well as controversy of infection control recommendation with regards to the use of PPE for HCW between institutions (table 1).(4-11) The aim of this narrative review is to of examine and 
summarise the available evidence to guide recommendation for the safety of $\mathrm{HCW}$ in the current pandemic.

\section{METHOD}

A literature search was conducted on the PubMed, MedLine, and Embase databases, and updated on 30 March 2020 with the keywords "personal protective equipment", "COVID 19", "n95", "health care worker", and "mortality". Bibliographic search was also undertaken. The abstracts were scanned to assess their appropriateness to be included in this narrative review.

\section{DISCUSSION}

\section{Transmission}

Respiratory droplet $(5-50 \mu \mathrm{m})$ is the main route of transmission, and may cause direct transmission via close contact (including the eye), or surface contamination.(1, 11-18) SARS-nCoV-2 can be transmitted via smaller aerosols with a droplet nuclei [?]5 $\mathrm{m}$, which can travel long distances and remain airborne for $2-4$ hours, depending on the ambient conditions.(19-21)

Certain events (eg coughing or sneezing, cardiopulmonary resuscitation) and aerosol generating procedures (AGP) (eg intubation, tracheostomy) can generate aerosols composed of smaller virus containing particles suspended in air.(17) SARS-nCoV-2 has been reported to remain infectious on inanimate surfaces at room temperature for up to 9 days.(22) SARS-CoV-2 is more stable on plastic and stainless steel than copper and cardboard.(21) It is detected up to 72 hours after application onto plastic, though the viral titre decayed exponentially.(21) The viral half-life was 6.8 hours on plastic, 5.6 hours on stainless steel.(21)

SARS-nCoV-2 is contagious during the latency period.(14, 15, 20, 23-27) Viral loads are highest in the first week (peaks at 3 to 5 days) after symptoms began and decline over the second week, especially in the nose than throat.(12, 15, 28-31) The viral loads in asymptomatic patients has been found to be similar to symptomatic patients. $(14,28)$ As such, when the COVID-19 status of patients is unknown, they are treated as if they are COVID-19 positive.(32) Prolonged viral shedding after recovery has also been reported.(26)

The transmission is reported to be between 2.1 and 4 cases per exposure.(1, 12, 20, 33-35) Systematic effort is required to reduce the transmission, which is influenced by various factors like: Pathogens, ventilation, air filtration, sterilization and PPE.(36) Respiratory protection is one of the key strategy for pandemic control, and to sustaining the HCW.

\section{Infection Rates of HCW}

$3.5-20 \%$ of $\mathrm{HCW}$ has been reported to be infected.(1, 37-40)

Initially, during the index outbreak in Wuhan, $13 \mathrm{HCWs}$ were infected.(41) They became the vectors of transmission to their colleagues and families, and $42000 \mathrm{HCWs}$ had to be brought in to treat patients as HCWs succumbed to COVID-19.(41, 42)

Wang $\mathrm{D}$ et al found nosocomial infection rate of $41.3 \%$.(43) In a case series of 138 patients, $29 \%$ ( $\mathrm{n}=40$ ) of these were HCW: $31(77.5 \%)$ worked on general wards, 7 (17.5\%) in emergency department, and $2(5 \%)$ in intensive care unit.(43) They reported patient who presented with abdominal symptom infected $>10 \mathrm{HCW}$ in the department.(43)

There was a report of a patient who was not identified as infected early in the Wuhan outbreak and proceeded to infected $14 \mathrm{HCW}$ during a stay for transnasal pituitary surgery.(44) However, the patient was transferred to 4 different wards and infected 10 neurosurgical nurses and 4 medical staff who had no PPE, rather than the operating room team and neurosurgeon.(29) Certain specialty like otolaryngology are disproportionately affected in most countries affected by the COVID-19 pandemic.(44)

Wang $\mathrm{X}$ et al found none of the 278 staff in the quarantined area with high exposure to the 28 patients with 2019-nCoV infection were infected.(45) They wore N95 respirators, disinfected and performed hand hygiene. Those in the Hepatobiliary Pancreatic Surgery, Trauma and Microsurgery, and Urology departments wore 
no masks, but disinfected and performed hand hygiene occasionally as there were not considered high risk in the early days of the outbreak in January(45). 10 of the 213 staff were confirmed to be infected, despite their lower risk of exposure.(45) The adjusted odds ration (OR) was 464.82.(45) The found no infections in two other hospitals in the N95 respirators groups.(45)

The increasing evidence of aerosol transmission during routine care in absence of AGPs, and concerns regarding efficient human transmission has resulted in recommendation for airborne precautions with a fit-tested N95 respirator and other PPE.(46, 47)

When the Chinese hospitals instituted full body PPE with goggles, head coverings, N95 respirators, hazmat suits, and they were housed away from their families, there was no new infections.(41) Since then, nosocomial transmission has not been a major amplifier of transmission in China, due to prevention and control.(31) It is believed that with the absence of major nosocomial outbreaks, these are acquired in their families where $85 \%$ of human-to-human transmission occurred.(12, 14, 15, 24, 31, 48)

\section{Lessons from SARS}

During the 2003 SARS outbreak, airway management protocols were developed by infection control experts who often lacked expertise in the management of airway problems, experts in airway management who lacked expertise in infection control, and caregivers with no experience in treating SARS patients.(49) $51 \%$ of the SARS cases were HCWs in Toronto despite these safety protocol.(50) This was also the finding in Singapore.(51) In other places, HCW accounted for $21 \%$ of the cases.(52) Oh M et al found institution of PPE prevented infections amongst HCW.(51) Perhaps this experience underlies the aggressive implementation of N95 respirators in some institutes regardless of the risk of exposure for all HCW, due to the high risk of mortality with COVID-19.(11, 12, 16, 23)

\section{Mortality Rate of HCW}

The mortality rate ranges from 1.4-3.83\%.(20, 23, 25, 27, 35, 37, 38, 46, 53-59)

China reported 3387 infected HCWs in Hubei alone, with at least 18 deaths (0.53\%) in late February.(60) Philippine Medial Association president reported ten doctors have died at the end of May, including the president of the Philippine Paediatric Society, due to the lack of PPE.(61) In Italy, on $28^{\text {th }}$ March 2020, $2629(20 \%)$ were infected, with 51 deaths $(1.94 \%) .(39,62)$ The numbers may be higher as those who died suddenly were not tested for the disease.

Once community spread of virus is confirmed, the hospital should institute guidelines for airborne and contact precautions during all AGPs.(1, 29)

\section{General Hygiene}

High degree of personal caution, and diligence in infection control procedure (hand and respiratory hygiene etc) are necessary. PPE is part of the measure within a package of prevention and control of pandemic, rather than a replacement of.

The education or re-training of proper selection and fit testing of PPE, training on donning, doffing and disposal of PPE training is vital, as up to $90 \%$ of staff do not use the correct doffing sequence or technique.(18, 63-65)

\section{Gowns and Gloves}

Guidance to the level of PPE depends on prevalence of COVID-19 in the community, the degree of community spread, availability, timeliness and accuracy of COVID-19 testing, and availability of PPE.(29)

A recent Cochrane review has found gown to be more protective than aprons against contamination (MD $-1.36,95 \%$ CI -1.78 - -0.94). Double gloving leads to less contamination compared to single gloving (RR 0.36, 95\% CI 0.16 - 0.78).(65) Alcohol-based hand rub during doffing may not lead to less contamination than the use of a hypochlorite base solution (MD 4, 95\% CI $0.47-34.24)$.(65) This has led to the recommendation 
of an assistant who guides the HCW through the process while watching for breaches and spraying chlorine as each item is removed during doffing.(65)

\section{Eye Protection}

Bischoff et al first reported direct evidence of transocular delivery of influenza virus in airborne form.(66) This trend was found in the current COVID-19 pandemic. One of the expert taskforce who visited Wuhan was infected despite fully gowned with protective suit and the N95 respirator.(12) His first symptom was unilateral conjunctivitis.(12) Safety glasses and or face shield has been recommended.(16)

\section{Masks and Respirators}

\subsection{Surgical Masks}

Surgical masks are fluid resistant. They filter particulate, droplets and bacteria. They are not designed for a tight seal, thus will allow unfiltered air to flow around the sides. The materials are not regulated for their ability to filter small particles and vary between models.

They are not considered respiratory protection. They are worn to protect HCWs from large droplets or sprays of infectious body fluids from patients that may be directly transmitted to the mucus membrane in the wearer's nose or mouth. When worn by patients, they reduce the concentration and amount of large infectious particles released when coughing, talking or sneezing, and thus infection risk to others.(67)

They have a reported failure rate of 10-90\%, which is inadequate for droplet nuclei protection.(68) Birschoff et al conducted a pilot study testing surgical masks against N95 respirators using a human exposure model, and they only protected 1 in 4 participants with influenza.(66)

\subsection{Respirators}

Respirators either filter the airborne particles and respiratory aerosol; or supply clean air to the respirator wearer; air-purifying, or atmosphere-supplying respirators. The most common respirators are filtering facepiece respirators and powered air-purifying respirators (PAPR).

The National Institute for Occupational Safety and Health (NIOSH) tests filters for the effects of loading (particle burden), temperature, and relative humidity and requires minimum filtration efficiency of $95 \%$, $99 \%$, or $99.97 \%$ using neutralized $0.075 \mu \mathrm{m}$ count median diameter solid aerosols at $85 \mathrm{~L} / \mathrm{min}$. (68) NIOSH evaluates the fit performance of some respiratory protective devices using human panels with specified facial dimensions.

\subsubsection{N95 Respirator}

These require certification by the NIOSH based on filter efficiencies with an assigned protection factor (APF) of 10.(69) They must have less than $5 \%$ penetration for aerosol with a mass median aerodynoamic diameter of 0.3 microns.(68) When the air is forced through the filtering material, contaminants are captured, which reduce the exposure to large droplets and small infectious particles in both directions.(67)

The two types are filtering facepiece respirator where the entire facepiece is made of filtering material, or elastomeric respirators that have replaceable filters or cartridges.(67)

Air-purifying respirators are further classified according to the efficiency at which they remove particles $(95 \%, 99 \%$ or $100 \%)$, and the resistance to oil.(36) N-series are not resistant to oil, R-series are resistant to oil, while P-series are oil proof. $(36,68)$

N95 is currently recommended for HCW who work within 2 meters of patients known to be, or suspected of being infected with SARS-CoV-2 and those performing AGP by most institutions (table 1).(10, 70-74)

Effectiveness

Birschoff et al found N95 respirators protected 4 of 5 participants in their influenza exposure model.(66) Birschoff et al's second study of live attenuated influenza vaccine strain (LAIV) in subjects wearing N95 
respirators in addition to goggles to prevent transocular transmission, was $90 \%$ effective (26 of 29 were PCR negative).(69)

A surgical mask overlay has been recommended to provide barrier protection in order to diminish contamination and attrition. $(75,76)$ This increases the breathing resistance and discomfort. $(76,77)$ However, the increased CO2 has not been shown to be clinically relevant after a 12-hour shift.(78) Increasing layers of PPE not only increase risk for confusion and contamination, it also increase the complexity of patient care.(79)

Evaluation of the deterioration of the filtration efficacy is difficult. Safety is affected by multiple variables that impact respirator function and contamination over time. Other factors than can potentially influence this include viral aerosol concentration, wearer's breathing rate, time of patient interaction, effect of humidity, diffusion, and particle retention efficiency of the mask. Research on the physiologic impacts of the long term N95 respirator use has been limited, and most are laboratory based. There is inadequate understanding of the number, size and dispersion of droplets containing live, infectious particles or aerosol.(6)

Respiratory pathogens may remain infectious on respirator surfaces for extended period, with the influenza A and B model surviving 8-12 hours on porous substrates, compared to 24-28 hours on non-porous surfaces. (8082) Some pathogens transfer well in high relative humidity.(83) However porous surfaces have a lower transfer rates due to entrapment of organisms within their matrix and the greater surface area in the recesses for attachment, hence less accessible to human hands. $(83,84)$ More than $99 \%$ pf pathogens remained trapped in the respirator after handling or following simulated cough or sneeze.(85-87) Respirators may be contaminated with other pathogens that have prolonged environmental survival (eg methicillin-resistant Staphylococcus aureus) resulting in the risk of self-inoculation.(88) The studies on the transfer efficiency of pathogens from mask to skin and other surfaces is limited to the lab setting, which may be different in clinical setting. Nevertheless, this can be mitigated by performing hand hygiene.

MacIntyre CR et al's randomised control trial (RCT) of HCW in the surgical masks, targeted N95 (intermittent use only in high risk procedure) and N95 arm (continuous use throughout shift) over 4 weeks found less respiratory infection (HR 0.56, 95\% CI $0.32-0.98$ ), influenza (RR 0.34, 95\% CI $0.1-1.11$ ) in the N95 arm, followed by the targeted N95 arm. $(47,89)$ This benefit persisted after adjusting for confounders by influenza vaccination and hand washing.(89) This is a more powerful study compared to Loeb M et al who had only 446 subjects, who found a trend towards increased protection with N95 from SARS thought it was not statistically significant.(90) The influenza rate found in their study (24\%) is the same as rates of influenza documented in nosocomial outbreaks in HCW without preventative interventions, and higher than other studies in unprotected HCW.(89-92) This was also found in MacIntyre CR et al's earlier study, where surgical mask group had double the infection outcomes compared to the N95 group.(93)

However, a recent systemic review and meta-analysis by Smith JD et al reported that there is insufficient data to determine the advantage of N95 over surgical masks.(6) Similarly Long Y et al's systemic review and meta-analysis found no statistically significant differences in preventing influenza (RR 1.09, 95\% CI 0.92 - 1.28), influenza-like illness (RR $0.61,95 \%$ CI $0.33-1.14$ ) and viral respiratory infection (RR 0.89 , 95\% CI 0.7 - 1.11).(7) However, when Loeb M et al's study was excluded, there was a significant effect on N95 preventing viral respiratory infections.(7) This should be interpreted with caution, as while laboratory studies confirmed it confer superior protection, there is often issues with compliance in real-world practice. This again defers in a pandemic situation.

\section{Extended Use or Limited Re-Use}

CDC advocated extended use (wearing the same N95 respirators for repeated close contact encounters with several patients without removing the respirator between patient encounters), over limited re-using to conserve supplies.(1, 82, 88) The decision is made by each institution, taking into account the characteristic of the respiratory pathogen and local conditions.(88) If no manufacturer guidance is available, limiting the number of reuse to no more than 5 uses per device to ensure an adequate safety margin. $(82,88,94)$ The filtration efficiency is reduced to below $95 \%$ for filters after 9 and 13 weeks of simulated reuse.(82) 
A Dutch study reported that the polypropylene masks (3M type 8822 masks), which do not contain cellulose can be used three times when sterilised twice with hydrogen peroxide in between use.(95) The mask is reported to be safe to be treated in hot air at $70^{*} \mathrm{C}$ for 30 minutes, or $125^{*} \mathrm{C}$ for 3 minutes but $90^{*} \mathrm{C}$ heat and $134 * \mathrm{C}$ steam deformed the mask. $(95,96)$

Most HCW can tolerate wearing N95 for up to 8 to 12 hours. $(1,82)$ Ang et al reported staff using it for the entire shift without removing it to conserve supply, unless soiled during the H1N1 pandemic.(97) However, most HCW are unwilling to wear N95 for the entire 8-hour work shift, as most need to take breaks, thus extended use beyond 4 hours is unlikely. $(1,78)$

N95 respirators should be discarded when grossly contaminated, damaged or difficult to breathe through.(1) Storage is in a clean, dry location, or in a single-use breathable container to avoid contamination and maintain the integrity.(1) In confirmed or highly suspected SARS-nCoV-2 cases, N95 respirators should be single-use only due to the risk of droplet spray contamination, degradation of filtration efficacy and mask fit, cross contamination during storage, doffing and donning of the respirator.(1)

Issues

N95 respirators are associated with diminished communication acuity, head and facial discomfort due to facial heat, pressure or pain, headache, itch and burning eyes. Some experience nausea, dizziness, difficulty concentration and issues with mechanical interference with duties.(75) J Wong et al reported $20 \%$ of their anaesthetist failed the fit-testing for the N95 respirator.(1) Eczema is a frequent complication of prolonged use, requiring medicated creams or ointments, or even adhesive bandage which may affect the fit of the mask. The irritation may increase the likelihood of inadvertent PPE protocol breach like mask touching or adjustment in an unconscious effort to relieve a source of irritation.(98) All these may impact on compliance over time, placing $\mathrm{HCW}$ at risk of infection.

On average, noncompliance in terms of adjusting the N95 respirator, touching the respirator or under it, face, or eye has been found to be 25.7 times per 12-hour shift.(78) Compliance is worst in those with higher BMIs.(78) Body movement when performing medical procedures by HCW may increase the risk of seal leakage.(99)

\subsubsection{Powered Air-Purifying Respirators (PAPR)}

PAPRs have a battery powered motor that draw air through a filter (for particles), catridges or canisters (for gases or vapours), then deliver filtered air under positive pressure to a hood or face piece. This positive pressure inside the facepiece reduces inward leakage of potentially contaminated air.(67) They may have a tight fitting half or full facepiece or a loose fitting facepiece, hood or helmet.

\section{Effectiveness}

Compared to N95 respirator, PAPRs have a higher protection factor with an APF of 25.(67) They filters $99.97 \%$ of particles $0.3 \mu \mathrm{m}$ and are oil proof, is more comfortable for prolonged periods, eliminates the fit problem and can be worn with eyewear and facial hair, and provides full face \& head coverage. $(1,23,100)$

While this the recommended respirator for AGPs, it is controversial due to a lack of evidence.(23) Bischoff et al's influenza exposure model found no detectable level of virus in all $(n=29)$ subjects with PAPR use.(69) Based on HCWs becoming infected during AGPs of patients with SARS despite the use of accepted universal precautions with gowns, caps, gloves, eye protections and N95 masks, PAPR has been recommended for high risk procedures on suspected or confirmed COVID-19 patients.(101, 102) DT Wong reported their institutional use of PAPR resulted in no infection during the SARS outbreak in Toronto.(102) Verbeek JH et al's 2019 Cochrane review found PAPR better than a PPE without such respirator (RR 0.27, 95\% CI $0.17-0.43) \cdot(65)$

Concurrent use with the N95 respirator to prevent transmission of infection is controversial.(77, 79) N95 in addition to PAPR during AGP has been recommended to supplement the respiratory protection, prevent passage of unfiltered exhalation gases from wearer to the immediate environment, and serve as a backup in 
the event of a PAPR mechanical failure, or over breathing which may create negative pressure in the PAPR and entrains unfiltered outside air.(103) This was found to multiplicatively increase the mean protection factor of the functioning PAPR, and even in a non-functioning PAPR.(103)

Issues

The main concern is the higher cost, challenges in training HCWs to safely remove PAPRs without contamination, the need for re-training if infrequently use, inability to re-use disposable filters between patients, the need for explicit decontamination and recycling of blower units, potential compromise of disposable components through inappropriate attempts to sterilise and reuse to conserve supply leading to infection risk, communication challenges due to the fan noise, and increased risk of infection from doffing the additional layers of PPE.(1, 23, 100, 104)

\section{CONCLUSION}

During a pandemic, transmission may not be elucidated especially early on. Transmission of viruses is multimodal, and in the setting of a novel pathogen with high case fatality with no proven effective interventions, policy makers should not be dogmatic about pathogens and their presumed mode of transmission. PPE that affords the best protection should be available for HCWs who risk their lives during the pandemic.

There is much to learn from this pandemic. We need to enhance the reserve medical supplies program, improve the system for allocation, distribution and utilisation of PPE. They should also be properly implemented to ensure we are ready for the next pandemic.

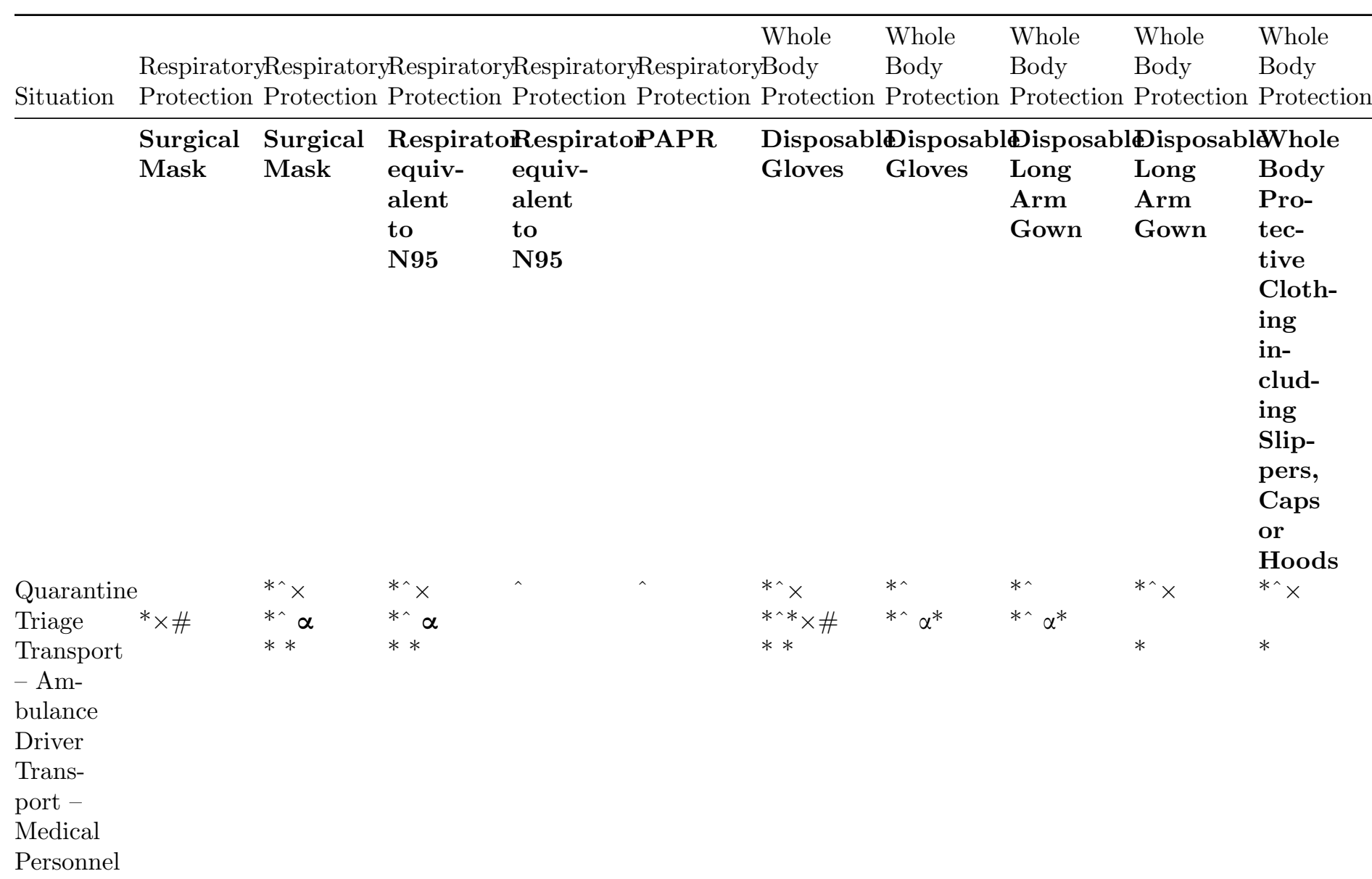




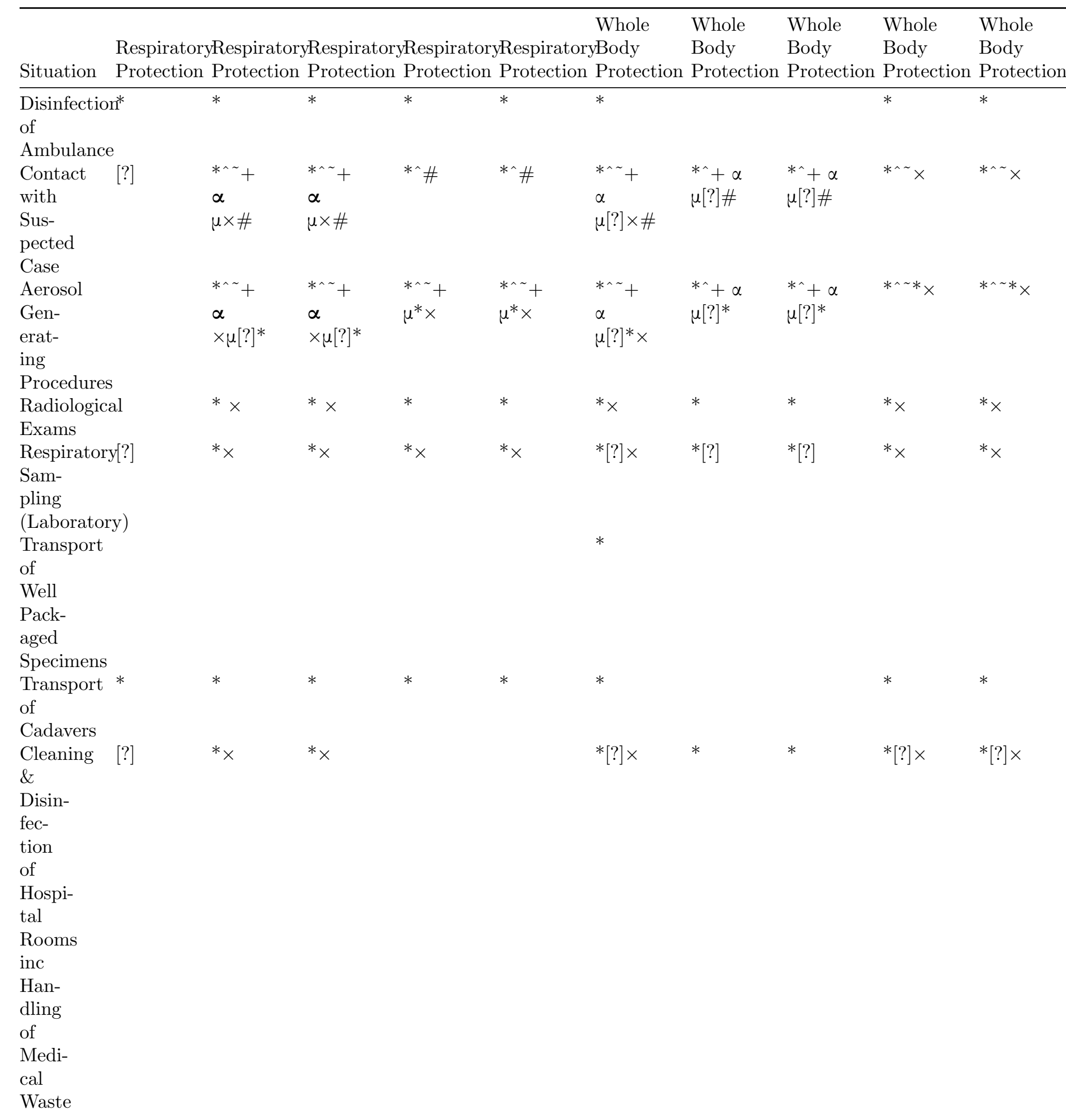




\begin{tabular}{|c|c|c|c|c|c|c|}
\hline Situation & $\begin{array}{l}\text { RespiratoryRespiratoryRespiratoryRespiratoryRespirator } \\
\text { Protection Protection Protection Protection Protection }\end{array}$ & $\begin{array}{l}\text { Whole } \\
\text { yBody } \\
\text { Protection }\end{array}$ & $\begin{array}{l}\text { Whole } \\
\text { Body } \\
\text { Protection }\end{array}$ & $\begin{array}{l}\text { Whole } \\
\text { Body } \\
\text { Protection }\end{array}$ & $\begin{array}{l}\text { Whole } \\
\text { Body } \\
\text { Protection }\end{array}$ & $\begin{array}{l}\text { Whole } \\
\text { Body } \\
\text { Protection }\end{array}$ \\
\hline $\begin{array}{l}\text { Transport } \\
\text { of } \\
\text { Medi- } \\
\text { cal } \\
\text { Waste }\end{array}$ & $*$ & $*$ & * & $*$ & $*$ & $*$ \\
\hline
\end{tabular}

Table 1: Summary of Recommended Personal Protective Equipment

* Huh S. How to train the health personnel for protecting themselves from novel coronavirus (COVID-19) infection during their patient or suspected case care. J Educ Eval Health Prof. 2020;17:10.

Double gloves should be worn considering the risk of tear or risk of exposure to infections in suspected and confirmed patient areas. If driver's seat not shielded or if there is a chance of contact with suspected or confirmed patient, wear whole body protective clothing.

advice guideline for the diagnosis and treatment of 2019 novel coronavirus (2019-nCoV) infected pneumonia (standard version). Mil Med Res. 2020;7(1):4.

Wong J, Goh QY, Tan Z, Lie SA, Tay YC, Ng SY, et al. Preparing for a COVID-19 pandemic: a review of operating room outbreak response measures in a large tertiary hospital in Singapore. Can J Anaesth. 2020.

+ Interim Infection Prevention and Control Recommendations for Patients with Suspected or Confirmed Coronavirus Disease 2019 (COVID-19) in Healthcare Settings. CDC. 19 March 2020.

a Yaneza M. ENTUK Guidelines for Changes in ENT During COVID-19 Pandemic. ENTUK. 2020.

Risk assessment re gloves. Shoe covers are not recommended. FFP3 rather than N95 for $\alpha$ in bold, otherwise FFP2 ie N95 equivalent for outpatients and areas with no direct patient contact.

$\mu$ Prunty S, HInton-Bayre A. Western AustralianENTRecommendations for PPE for Aerosol GeneratingProcedures during COVID-19 Pandemic. 25 March 2020.

[?] Rational use of personal protective equipment (PPE) for coronavirus disease (COVID-19). WHO. 19 March 2020.

For triage, apart from maintaining 1 mtre distance, no PPE is required. In the outpatient area, patients with respiratory symptoms are provided with medical mask if tolerated.

* Guidance for Health Care Workers Performing Aerosol Generating Medical Procedures During the COVID10 Pandemic. CSO-HNS. 26 March 2020.

Level 2 PPE even in COVID negative patients. For COVID positive, 2 layers of protectivec qeuipment consisting of a first layer of globes, fluid repellent surgical gown, head cover that covers the neck and N95, followed by a seoncd laryer of all three with a second mark being a regular surgical mask. Eye protection that seals the face is preferred.

$\times$ Handbook of COVID-19 Prevention and Treatment. Zhejiang University. 24 March 2020.

All staff must wear surgical masks. Full face respiratory protective devices or PAPR for level 3 protection.

\# Guidelines for Otolaryngologists, Head and Neck Surgeons on Personal Protection Equipment in the COVID-19 Pandemic. NZSOHNS. 2020.

Surgical cap in addition to gown. 
Ti LK, Ang LS, Foong TW, Ng BSW. What we do when a COVID-19 patient needs an operation: operating room preparation and guidance. Can J Anaesth. 2020.

\section{REFERENCES}

1. Wong J, Goh QY, Tan Z, Lie SA, Tay YC, Ng SY, et al. Preparing for a COVID-19 pandemic: a review of operating room outbreak response measures in a large tertiary hospital in Singapore. Can J Anaesth. 2020.

2. Wang X, Zhang X, He J. Challenges to the system of reserve medical supplies for public health emergencies: reflections on the outbreak of the severe acute respiratory syndrome coronavirus 2 (SARS-CoV-2) epidemic in China. Biosci Trends. 2020;14(1):3-8.

3. MacIntyre CR, Chughtai AA, Seale H, Richards GA, Davidson PM. Respiratory protection for healthcare workers treating Ebola virus disease (EVD): are facemasks sufficient to meet occupational health and safety obligations? Int J Nurs Stud. 2014;51(11):1421-6.

4. Chughtai AA, Seale H, MacIntyre CR. Availability, consistency and evidence-base of policies and guidelines on the use of mask and respirator to protect hospital health care workers: a global analysis. BMC Res Notes. $2013 ; 6: 216$.

5. Australian Health Management Plan for Pandemic Influenza. Australian Government Department of Health. August 2019.

6. Smith JD, MacDougall CC, Johnstone J, Copes RA, Schwartz B, Garber GE. Effectiveness of N95 respirators versus surgical masks in protecting health care workers from acute respiratory infection: a systematic review and meta-analysis. Cmaj. 2016;188(8):567-74.

7. Long Y, Hu T, Liu L, Chen R, Guo Q, Yang L, et al. Effectiveness of N95 respirators versus surgical masks against influenza: A systematic review and meta-analysis. J Evid Based Med. 2020.

8. CADTH Rapid Response Reports. Respiratory Precautions for Protection from Bioaerosols or Infectious Agents: A Review of the Clinical Effectiveness and Guidelines. Ottawa (ON): Canadian Agency for Drugs and Technologies in Health

Copyright (C) 2014 Canadian Agency for Drugs and Technologies in Health.; 2014.

9. Chung SJ, Ling ML, Seto WH, Ang BS, Tambyah PA. Debate on MERS-CoV respiratory precautions: surgical mask or N95 respirators? Singapore Med J. 2014;55(6):294-7.

10. Guidance on Preparing Workplaces for COVID-19. OSHA. 2020.

11. Rational use of personal protective equipment (PPE) for coronavirus disease (COVID-19). WHO. 19 March 2020.

12. Jin YH, Cai L, Cheng ZS, Cheng H, Deng T, Fan YP, et al. A rapid advice guideline for the diagnosis and treatment of 2019 novel coronavirus (2019-nCoV) infected pneumonia (standard version). Mil Med Res. 2020;7(1):4.

13. Schwartz J, King CC, Yen MY. Protecting Health Care Workers during the COVID-19 Coronavirus Outbreak -Lessons from Taiwan's SARS response. Clin Infect Dis. 2020.

14. Chan JF, Yuan S, Kok KH, To KK, Chu H, Yang J, et al. A familial cluster of pneumonia associated with the 2019 novel coronavirus indicating person-to-person transmission: a study of a family cluster. Lancet. 2020;395(10223):514-23.

15. Yu P, Zhu J, Zhang Z, Han Y, Huang L. A familial cluster of infection associated with the 2019 novel coronavirus indicating potential person-to-person transmission during the incubation period. J Infect Dis. 2020. 
16. Huh S. How to train the health personnel for protecting themselves from novel coronavirus (COVID-19) infection during their patient or suspected case care. J Educ Eval Health Prof. 2020;17:10.

17. Brewster DJ, Chrimes NC, Do TB, Fraser K, Groombridge CJ, Higgs A, et al. Consensus statement: Safe Airway Society principles of airway management and tracheal intubation specific to the COVID-19 adult patient group. MJA. 16 March 2020.

18. Phan LT, Sweeney D, Maita D, Moritz DC, Bleasdale SC, Jones RM. Respiratory viruses on personal protective equipment and bodies of healthcare workers. Infect Control Hosp Epidemiol. 2019;40(12):1356-60.

19. Yassi A, Moore D, Fitzgerald JM, Bigelow P, Hon CY, Bryce E. Research gaps in protecting healthcare workers from SARS and other respiratory pathogens: an interdisciplinary, multi-stakeholder, evidence-based approach. J Occup Environ Med. 2005;47(1):41-50.

20. Han Q, Lin Q, Jin S, You L. Coronavirus 2019-nCoV: A brief perspective from the front line. J Infect. 2020;80(4):373-7.

21. van Doremalen N, Bushmaker T, Morris DH, Holbrook MG, Gamble A, Williamson BN, et al. Aerosol and Surface Stability of SARS-CoV-2 as Compared with SARS-CoV-1. N Engl J Med. 2020.

22. Kampf G, Todt D, Pfaender S, Steinmann E. Persistence of coronaviruses on inanimate surfaces and their inactivation with biocidal agents. J Hosp Infect. 2020;104(3):246-51.

23. Wax RS, Christian MD. Practical recommendations for critical care and anesthesiology teams caring for novel coronavirus (2019-nCoV) patients. Can J Anaesth. 2020.

24. Zhang H. Early lessons from the frontline of the 2019-nCoV outbreak. Lancet. 2020;395(10225):687.

25. Koh D. Occupational risks for COVID-19 infection. Occup Med (Lond). 2020;70(1):3-5.

26. Rothe C, Schunk M, Sothmann P, Bretzel G, Froeschl G, Wallrauch C, et al. Transmission of 2019-nCoV Infection from an Asymptomatic Contact in Germany. N Engl J Med. 2020;382(10):970-1.

27. Mizumoto K, Chowell G. Estimating Risk for Death from 2019 Novel Coronavirus Disease, China, January-February 2020. Emerg Infect Dis. 2020;26(6).

28. Zou L, Ruan F, Huang M, Liang L, Huang H, Hong Z, et al. SARS-CoV-2 Viral Load in Upper Respiratory Specimens of Infected Patients. New England Journal of Medicine. 2020;382(12):1177-9.

29. Guidance for Health Care Workers Performing Aerosol Generating Medical Procedures During the COVID-10 Pandemic. CSO-HNS. 26 March 2020.

30. Handbook of COVID-19 Prevention and Treatment. Zhejiang University. 24 March 2020.

31. Bedford J, Enria D, Giesecke J, Heymann DL, Ihekweazu C, Kobinger G, et al. COVID-19: towards controlling of a pandemic. Lancet. 2020.

32. Otolaryngologists and the COVID-19 Pandemic. AAOHNS. 23 March 2020.

33. Liu Y, Li J, Feng Y. Critical care response to a hospital outbreak of the 2019-nCoV infection in Shenzhen, China. Crit Care. 2020;24(1):56.

34. Remuzzi A, Remuzzi G. COVID-19 and Italy: what next? Lancet. 2020.

35. Jung SM, Akhmetzhanov AR, Hayashi K, Linton NM, Yang Y, Yuan B, et al. Real-Time Estimation of the Risk of Death from Novel Coronavirus (COVID-19) Infection: Inference Using Exported Cases. J Clin Med. 2020;9(2).

36. Chao YS, Spry C. CADTH Rapid Response Reports. The Use of N95 Respirators for Protection against Droplet Borne Illness: A Review of the Clinical Effectiveness and Guidelines. Ottawa (ON): Canadian Agency for Drugs and Technologies in Health 
Copyright (C) 2017 Canadian Agency for Drugs and Technologies in Health.; 2017.

37. Guan WJ, Ni ZY, Hu Y, Liang WH, Ou CQ, He JX, et al. Clinical Characteristics of Coronavirus Disease 2019 in China. N Engl J Med. 2020.

38. Lai CC, Wang CY, Wang YH, Hsueh SC, Ko WC, Hsueh PR. Global epidemiology of coronavirus disease 2019: disease incidence, daily cumulative index, mortality, and their association with country healthcare resources and economic status. Int J Antimicrob Agents. 2020:105946.

39. The L. COVID-19: protecting health-care workers. Lancet. 2020;395(10228):922.

40. Rohan P, O'Reilly MK, Gibney B, Nason GJ. Supply of Personal Protective Equipment (PPE) During the Covid-19 Pandemic. Ir Med J. 2020;113(4):66.

41. Gawande A. Keeping the Coronavirus from Infecting Health-Care Workers. The New Yorker. 21 MArch 2020 .

42. Zhang Z, Yao W, Wang Y, Long C, Fu X. Wuhan and Hubei COVID-19 mortality analysis reveals the critical role of timely supply of medical resources. J Infect. 2020.

43. Wang D, Hu B, Hu C, Zhu F, Liu X, Zhang J, et al. Clinical Characteristics of 138 Hospitalized Patients With 2019 Novel Coronavirus-Infected Pneumonia in Wuhan, China. Jama. 2020.

44. Patel ZM, Fernandez-Miranda J, Hwang PH, Nayak JV, Dodd R, Sajjadi H, et al. Precautions for Endoscopic Transnasal Skull Base Surgery During the COVID-19 Pandemic. Neurosurg. 2020.

45. Wang X, Pan Z, Cheng Z. Association between 2019-nCoV transmission and N95 respirator use. J Hosp Infect. 2020.

46. Huang C, Wang Y, Li X, Ren L, Zhao J, Hu Y, et al. Clinical features of patients infected with 2019 novel coronavirus in Wuhan, China. Lancet. 2020;395(10223):497-506.

47. MacIntyre CR, Chughtai AA, Rahman B, Peng Y, Zhang Y, Seale H, et al. The efficacy of medical masks and respirators against respiratory infection in healthcare workers. Influenza Other Respir Viruses. 2017;11(6):511-7.

48. Li Q, Guan X, Wu P, Wang X, Zhou L, Tong Y, et al. Early Transmission Dynamics in Wuhan, China, of Novel Coronavirus-Infected Pneumonia. N Engl J Med. 2020;382(13):1199-207.

49. Caputo KM, Byrick R, Chapman MG, Orser BJ, Orser BA. Intubation of SARS patients: infection and perspectives of healthcare workers. Can J Anaesth. 2006;53(2):122-9.

50. Booth CM, Matukas LM, Tomlinson GA, Rachlis AR, Rose DB, Dwosh HA, et al. Clinical features and short-term outcomes of 144 patients with SARS in the greater Toronto area. Jama. 2003;289(21):2801-9.

51. Oh VM, Lim TK. Singapore's experience of SARS. Clin Med (Lond). 2003;3(5):448-51.

52. Chang, Xu H, Rebaza A, Sharma L, Dela Cruz CS. Protecting health-care workers from subclinical coronavirus infection. Lancet Respir Med. 2020;8(3):e13.

53. Lai THT, Tang EWH, Chau SKY, Fung KSC, Li KKW. Stepping up infection control measures in ophthalmology during the novel coronavirus outbreak: an experience from Hong Kong. Graefes Arch Clin Exp Ophthalmol. 2020.

54. Wang H, Wang S, Yu K. COVID-19 infection epidemic: the medical management strategies in Heilongjiang Province, China. Crit Care. 2020;24(1):107.

55. Ji Y, Ma Z, Peppelenbosch MP, Pan Q. Potential association between COVID-19 mortality and healthcare resource availability. Lancet Glob Health. 2020;8(4):e480. 
56. Sun Q, Qiu H, Huang M, Yang Y. Lower mortality of COVID-19 by early recognition and intervention: experience from Jiangsu Province. Ann Intensive Care. 2020;10(1):33.

57. Roussel Y, Giraud-Gatineau A, Jimeno MT, Rolain JM, Zandotti C, Colson P, et al. SARS-CoV-2: fear versus data. Int J Antimicrob Agents. 2020:105947.

58. Battegay M, Kuehl R, Tschudin-Sutter S, Hirsch HH, Widmer AF, Neher RA. 2019-novel Coronavirus (2019-nCoV): estimating the case fatality rate - a word of caution. Swiss Med Wkly. 2020;150:w20203.

59. Wujtewicz M, Dylczyk-Sommer A, Aszkiełowicz A, Zdanowski S, Piwowarczyk S, Owczuk R. COVID19 - what should anaethesiologists and intensivists know about it? Anaesthesiology Intensive Therapy. 2020;52(1):34-41.

60. Alice SU. Doctors and nurses fighting coronavirus in China die of both infection and fatigue. LA Times. 25 February 2020.

61. Santos J. 10 doctors died of COVID-19. GMA News. 28 March 2020.

62. Redazione. Elenco dei Medici caduti nel corso dell'epidemia di Covid-19. FNOMCeO. 27 March 2020.

63. Phan LT, Maita D, Mortiz DC, Weber R, Fritzen-Pedicini C, Bleasdale SC, et al. Personal protective equipment doffing practices of healthcare workers. J Occup Environ Hyg. 2019;16(8):575-81.

64. John A, Tomas ME, Cadnum JL, Mana TS, Jencson A, Shaikh A, et al. Are health care personnel trained in correct use of personal protective equipment? Am J Infect Control. 2016;44(7):840-2.

65. Verbeek JH, Rajamaki B, Ijaz S, Tikka C, Ruotsalainen JH, Edmond MB, et al. Personal protective equipment for preventing highly infectious diseases due to exposure to contaminated body fluids in healthcare staff. Cochrane Database Syst Rev. 2019;7:Cd011621.

66. Bischoff WE, Reid T, Russell GB, Peters TR. Transocular entry of seasonal influenza-attenuated virus aerosols and the efficacy of n95 respirators, surgical masks, and eye protection in humans. J Infect Dis. 2011;204(2):193-9.

67. Hospital Respiratory Protection Program Toolkit. NIOSH. May 2015.

68. Oberg T, Brosseau LM. Surgical mask filter and fit performance. Am J Infect Control. 2008;36(4):276-82.

69. Bischoff WE, Turner J, Russell G, Blevins M, Missaiel E, Stehle J. How well do N95 respirators protect healthcare providers against aerosolized influenza virus? Infect Control Hosp Epidemiol. 2018:1-3.

70. Interim Infection Prevention and Control Recommendations for Patients with Suspected or Confirmed Coronavirus Disease 2019 (COVID-19) in Healthcare Settings. CDC. 19 March 2020.

71. Yaneza M. ENTUK Guidelines for Changes in ENT During COVID-19 Pandemic. ENTUK. 2020.

72. Prunty S, HInton-Bayre A. Western AustralianENTRecommendations for PPE for Aerosol GeneratingProcedures during COVID-19 Pandemic. 25 March 2020.

73. Malhotra N, Gupta N, Ish S, Ish P. COVID-19 in intensive care. Some necessary steps for health care workers. Monaldi Arch Chest Dis. 2020;90(1).

74. Ti LK, Ang LS, Foong TW, Ng BSW. What we do when a COVID-19 patient needs an operation: operating room preparation and guidance. Can J Anaesth. 2020.

75. Radonovich LJ, Jr., Cheng J, Shenal BV, Hodgson M, Bender BS. Respirator tolerance in health care workers. Jama. 2009;301(1):36-8.

76. Roberge RJ. Effect of surgical masks worn concurrently over N95 filtering facepiece respirators: extended service life versus increased user burden. J Public Health Manag Pract. 2008;14(2):E19-26. 
77. Roberge RJ. Evaluation of the rationale for concurrent use of N95 filtering facepiece respirators with loose-fitting powered air-purifying respirators during aerosol-generating medical procedures. Am J Infect Control. 2008;36(2):135-41.

78. Rebmann T, Carrico R, Wang J. Physiologic and other effects and compliance with long-term respirator use among medical intensive care unit nurses. Am J Infect Control. 2013;41(12):1218-23.

79. Nicolle L. SARS safety and science. Can J Anaesth. 2003;50(10):983-5, 5-8.

80. Casanova L, Rutala WA, Weber DJ, Sobsey MD. Coronavirus survival on healthcare personal protective equipment. Infect Control Hosp Epidemiol. 2010;31(5):560-1.

81. Coulliette AD, Perry KA, Edwards JR, Noble-Wang JA. Persistence of the 2009 pandemic influenza A (H1N1) virus on N95 respirators. Appl Environ Microbiol. 2013;79(7):2148-55.

82. Fisher EM, Shaffer RE. Considerations for recommending extended use and limited reuse of filtering facepiece respirators in health care settings. J Occup Environ Hyg. 2014;11(8):D115-28.

83. Lopez GU, Gerba CP, Tamimi AH, Kitajima M, Maxwell SL, Rose JB. Transfer efficiency of bacteria and viruses from porous and nonporous fomites to fingers under different relative humidity conditions. Appl Environ Microbiol. 2013;79(18):5728-34.

84. Rusin P, Maxwell S, Gerba C. Comparative surface-to-hand and fingertip-to-mouth transfer efficiency of gram-positive bacteria, gram-negative bacteria, and phage. J Appl Microbiol. 2002;93(4):585-92.

85. Fisher EM, Richardson AW, Harpest SD, Hofacre KC, Shaffer RE. Reaerosolization of MS2 bacteriophage from an N95 filtering facepiece respirator by simulated coughing. Ann Occup Hyg. 2012;56(3):315-25.

86. Kennedy NJ, Hinds WC. Release of simulated anthrax particles from disposable respirators. J Occup Environ Hyg. 2004;1(1):7-10.

87. Birkner JS, Fung D, Hinds WC, Kennedy NJ. Particle release from respirators, part I: determination of the effect of particle size, drop height, and load. J Occup Environ Hyg. 2011;8(1):1-9.

88. Phan T. Novel coronavirus: From discovery to clinical diagnostics. Infect Genet Evol. 2020;79:104211.

89. MacIntyre CR, Wang Q, Seale H, Yang P, Shi W, Gao Z, et al. A randomized clinical trial of three options for N95 respirators and medical masks in health workers. Am J Respir Crit Care Med. 2013;187(9):960-6.

90. Loeb M, Dafoe N, Mahony J, John M, Sarabia A, Glavin V, et al. Surgical mask vs N95 respirator for preventing influenza among health care workers: a randomized trial. Jama. 2009;302(17):1865-71.

91. Elder AG, O'Donnell B, McCruden EA, Symington IS, Carman WF. Incidence and recall of influenza in a cohort of Glasgow healthcare workers during the 1993-4 epidemic: results of serum testing and questionnaire. Bmj. 1996;313(7067):1241-2.

92. Salgado CD, Farr BM, Hall KK, Hayden FG. Influenza in the acute hospital setting. Lancet Infect Dis. 2002;2(3):145-55.

93. MacIntyre CR, Wang Q, Cauchemez S, Seale H, Dwyer DE, Yang P, et al. A cluster randomized clinical trial comparing fit-tested and non-fit-tested N95 respirators to medical masks to prevent respiratory virus infection in health care workers. Influenza Other Respir Viruses. 2011;5(3):170-9.

94. Bergman MS, Viscusi DJ, Zhuang Z, Palmiero AJ, Powell JB, Shaffer RE. Impact of multiple consecutive donnings on filtering facepiece respirator fit. Am J Infect Control. 2012;40(4):375-80.

95. van Leeuwenhoeklaan A. Reuse of FFP2 Masks. Rijksinstituut voor Voksgezondheid en Milieu. 18 March 2020.

96. Tsai PP. Information and FAQs on Performance, Protection, and Sterilization of Masks Against COVID19. 25 March 2020. 
97. Ang B, Poh BF, Win MK, Chow A. Surgical masks for protection of health care personnel against pandemic novel swine-origin influenza A (H1N1)-2009: results from an observational study. Clin Infect Dis. 2010;50(7):1011-4.

98. Kantor J. Behavioral considerations and impact on personal protective equipment (PPE) use: Early lessons from the coronavirus (COVID-19) outbreak. J Am Acad Dermatol. 2020.

99. Suen LKP, Yang L, Ho SSK, Fung KHK, Boost MV, Wu CST, et al. Reliability of N95 respirators for respiratory protection before, during, and after nursing procedures. Am J Infect Control. 2017;45(9):974-8.

100. Roberts V. To PAPR or not to PAPR? Can J Respir Ther. 2014;50(3):87-90.

101. Christian MD, Loutfy M, McDonald LC, Martinez KF, Ofner M, Wong T, et al. Possible SARS coronavirus transmission during cardiopulmonary resuscitation. Emerg Infect Dis. 2004;10(2):287-93.

102. Wong DT. Protection protocol in intubation of suspected SARS patients. Can J Anaesth. 2003;50(7):7478.

103. Roberge MR, Vojtko MR, Roberge RJ, Vojtko RJ, Landsittel DP. Wearing an N95 respirator concurrently with a powered air-purifying respirator: effect on protection factor. Respir Care. 2008;53(12):1685-90.

104. Khoo KL, Leng PH, Ibrahim IB, Lim TK. The changing face of healthcare worker perceptions on powered air-purifying respirators during the SARS outbreak. Respirology. 2005;10(1):107-10. 